\title{
Subcutaneous fat pattern among urban pre-school children in India
}

\author{
K. Saluja ${ }^{1,2}$, S. Kapoor ${ }^{1}$, G. Mc Neill ${ }^{2}$ and W. C. Smith ${ }^{2}$ \\ ${ }^{1}$ Department of Anthropology, University of Delhi, Delhi, India and ${ }^{2}$ Institute of Applied Health Sciences, University of \\ Aberdeen, Aberdeen AB25 2ZD, UK
}

Health risks of overweight and obesity in children are related to body fat content ${ }^{(1)}$ with the regional distribution of fat being an independent health risk. The aim of the present study is to determine body composition in Indian preschool children and to describe variation in fat distribution according to age, sex and nutritional status. Data were collected on a cross-sectional sample of 657 pre-school and primary school children, aged 2-6 years, from 12 play centres in Delhi, India. Height, weight and skin-fold thickness (SFT) at biceps, triceps, suprailliac, subscapular, abdomen, thigh, medial calf and posterior calf sites were measured. BMI for age and gender was used to classify children as underweight (<3rd percentile) or overweight ( $>85$ th percentile) using WHO standards $(2006)$ : $8.5 \%$ of children were overweight and $28.5 \%$ were underweight. Body fat percentage (BF \%) was calculated from skin-fold thicknesses ${ }^{(2)}$. Fat mass $(\mathrm{FM})$, fatfree mass (FFM), fat mass index (FMI) and fat-free mass index (FFMI) were also computed. The mean difference in body composition parameters age was assessed by student's $t$-test. The subcutaneous fat distribution pattern (FDP) was obtained by arranging all SFT sites in ascending order of thickness for the age, sex and nutrition status groups. The fat percentage decreased from age 2 years to 6 years in both sexes. BF\% was significantly higher in girls $(P<0.01)$, while FFM and FFMI were significantly higher in boys $(P<0.001)$ for all age groups. FM and FMI were higher in girls and this was significant $(P<0.05)$ up to 4.5 years. SFT plotted in ascending order showed that subcutaneous FDP remained consistent with increase in age within both sexes with a slight variation between boys and girls.

\begin{tabular}{ll}
\hline $\begin{array}{l}\text { Male } \\
\text { Female }\end{array}$ & $\begin{array}{l}\text { suprailliac }<\text { biceps }<\text { subscapular }<\text { abdomen }<\text { triceps }<\text { calfmedial }<\text { calfposterior }<\text { thigh } \\
\text { biceps }<\text { suprailliac }<\text { subscapular }<\text { abdomen }<\text { triceps }<\text { calfmedial }<\text { calfposterior }<\text { thigh }\end{array}$ \\
\hline
\end{tabular}
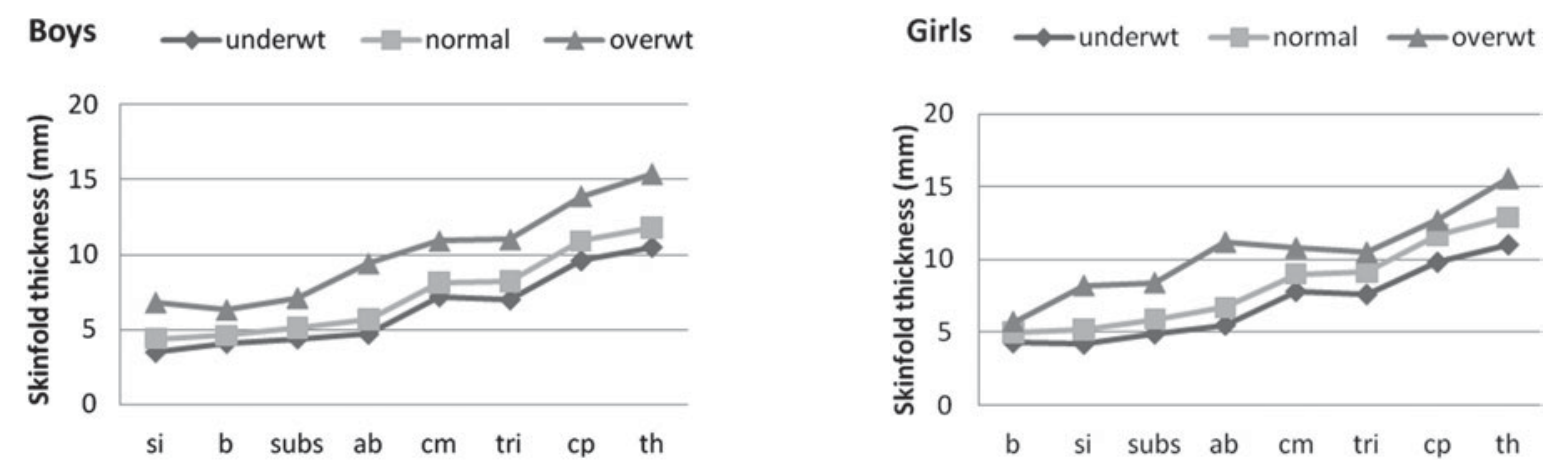

The influence of underweight and overweight on FDP showed sexual dimorphism. The increase was not uniform at all sites showing differential fat deposition at different levels of nutritional status. Truncal fat (abdomen and suprailliac SFT) was more sensitive to overweight among girls and showed greater tendency to fat deposition, while in boys there was a more uniform increase in fat on all sites.

1. Williams DP, Going SB, Lohman TG et al. (1992) Body fatness and risk for elevated blood pressure, total cholesterol and serum lipoprotein ratios in children and adolescents. Am J Public Health 82, 358-363.

2. Slaughter MH, Lohman TG, Boileau RA et al. (1998) Skinfold equations for estimation of body fatness in children and youth. Hum Biol 60, 709-723. 